\title{
STRUKTUR POPULASI IKAN GULAMAH (Johnius trachycephalus P.) DI SUNGAI BARUMUN KABUPATEN LABUHAN BATU SUMATERA UTARA
}

\author{
Gunaria Siagian, Hesti Wahyuningsih, Ternala Barus \\ Departemen Biologim Fakultas Matematika dan Ilmu Pengetahuan Alam \\ Universitas Sumatera Utara
}

\begin{abstract}
ABSTRAK
Ikan Gulamah (Johnius trachycephalus) merupakan salah satu jenis ikan demersal yang banyak ditangkap oleh nelayan dengan menggunakan trammel net dan gill net, payang dan pukat. Penangkapan ikan Gulamah di sungai Barumun Kabupaten Labuhan Batu dilakukan setiap hari tanpa batas. Eksploitasi yang tidak terkendalikan dapat mengakibatkan menipisnya stok ikan. Penelitian ini bertujuan untuk mengetahui kepadatan populasi, rasio kelamin, pola pertumbuhan ikan dan hubungan faktor fisik- kimia air dengan kepadatan ikan gulamah (Johnius trachycephalus) di sungai Barumun Kabupaten Labuhan Batu. Pengambilan sampel menggunakan metode purposive sampling pada 5 stasiun penelitian. Pengambilan sampel ikan dilakukan dengan memasang jaring sebanyak 5 ulangan pada masing-masing stasiun dan pada setiap ulangan jaring dibiarkan 1 jam di dalam air. Hasil penelitian menunjukkan bahwa kepadatan ikan Gulamah tertinggi di stasiun I yaitu 0,019 ind/m² (37 ekor), terendah di stasiun $\mathrm{V}$ yaitu $0,003 \mathrm{ind} / \mathrm{m}^{2}$ (6 ekor). Rasio kelamin tertinggi di stasiun IV yaitu 1:8 dan terendah di stasiun I yaitu 1:1,5. Pola pertumbuhan ikan gulamah di stasiun I allometrik positif sedangkan di stasiun II-V allometrik negatif. Ikan gulamah yang didapatkan selama penelitian sebanyak 68 individu. Ikan jantan panjangnya berkisar 10,5 cm - 21,5 cm, ikan betina panjangnya 10,5 cm - 21,6 $\mathrm{cm}$. Frekuensi panjang yang terbanyak (modus) 18,5 cm - $20 \mathrm{~cm}$. Suhu dan kejenuhan oksigen berkolerasi sangat kuat terhadap kepadatan ikan gulamah (Johnius trachycephalus).
\end{abstract}

Kata kunci : ikan Gulamah, struktur populasi, sungai Barumun

\section{THE STRUCTURE OF Johnius trachycephalus P. FIST IN BARUMUN RIVER AT LABUHAN BATU REGENCY OF NORTH SUMATRA}

\begin{abstract}
Gulamah fist (Johnius trachycephalus) is one of kind demersal fish that catched by fisherman by using trammel net and gill net, payang and dragnet. They did it almost every day. This exploitation is uncontrol, it can wiped out of the fish, we make this research to know about the population genre of ratio, the form of growing and the relation of physic - water chemistry with the population of gulamah fish. We take the sample of fish by using net Five times on each station and each repetition the net lets an hour on the water. The result indicates that the highest population of gulamah is on the first station is $0,019 \mathrm{Ind} / \mathrm{m}^{2}(37$ species). The lowest is on the fifth station is $0,003 \mathrm{ind} / \mathrm{m}^{2}$ ( 6 species). The highest gender in the fourth station is $1: 8$ and the loulest is on the first station 1:1,5 the form of growing is on the first station allometrik positive while on the second station, $\mathrm{V}$ allometrik negatif. During the research we can find 68 kinds of gulamah fish. The length male fish about $10,5 \mathrm{~cm}-21 \mathrm{~cm}$ and, the female fish is $10,5 \mathrm{~cm}$ $-21,6 \mathrm{~cm}$, the frequency of length is most $18,5 \mathrm{~cm}-20 \mathrm{~cm}$. The temperature and satiation oxygen has strong coleration with density of gulamah (Johnius Trachycephalus).
\end{abstract}

The key word : Gulamah fish, the structures of population Barumun river.

\section{Pendahuluan}

Sungai Barumun mengalir di sepanjang wilayah Kecamatan Panai Hulu Kabupaten Labuhan Batu. Sungai Barumun merupakan sungai besar dengan lebar antara $750 \mathrm{~m}$ 1050 m, dengan sungai kecil sebagai anak sungai/cabang. Muara dari sungai Barumun tersebut adalah Selat Malaka (Oseanografi, 1987). Sungai Barumun banyak digunakan oleh masyarakat sekitar untuk berbagai aktivitas misalnya pembuangan limbah industri, limbah rumah tangga, tempat 
pelelangan ikan, pelabuhan dan penangkapan ikan. Aktivitas tersebut mengakibatkan sungai Barumun tercemar dengan warna airnya yang semakin keruh. Sungai Barumun merupakan sumber penghasil ikan bagi masyarakat kecamatan Panai Hulu dan sekitarnya. Hasil tangkapan nelayan di sungai Barumun ditemukan berbagai jenis ikan, salah satunya adalah ikan gulamah (Johnius trachycephalus) Ikan gulamah (J. trachycephalus) termasuk dalam ordo Perciformes, familia Scinidae. Nama lokal ikan ini adalah Siliman, Tiga wajah, Krokot, Tengkerong, Sangeh Burung, Gelomo, Gulamo dan ikan kepala batu.

Ikan Gulamah (J. trachycephalus) merupakan salah satu jenis ikan yang banyak diminati masyarakat. Selain dagingnya yang lembut dan tebal ikan gulamah mempunyai nilai ekonomi sebagai ikan konsumsi dengan harga terjangkau masyarakat umumnya yaitu sekitar 25.000/kg. Ikan ini banyak dijual di pasar tradisional dengan bentuk yang sudah diasinkan. Saat ini ikan gulamah paling banyak ditemukan di wilayah Kalimantan. Ikan ini terdistribusi di Pulau Sumatera, Kalimantan dan Thailand. Habitatnya di perairan pantai yang dangkal, estuaria dan sungai. Penelitian tentang pertumbuhan ikan Gulamah sudah pernah dilakukan di daerah lain, misalnya di Cilacap. Berdasarkan data TPI PPS Cilacap tahun 2000 - 2007 menunjukkan bahwa sifat pertumbuhan ikan gulamah jantan adalah allometrik negatif, sedangkan ikan betina isometrik. Ukuran rata-rata tertangkap ikan Gulamah jantan sebesar $150 \mathrm{~mm}$, ikan Gulamah betina sebesar $154 \mathrm{~mm}$. Nisbah kelamin antara jantan dengan betina sebesar 1:1,86 masih terjamin terjadinya reproduksi alamiahnya. Tingkat eksploitasi ikan Gulamah masih rendah (Mahardhini, 2008).

Ikan Gulamah (J. trachycephalus) termasuk jenis ikan karnivora. Ikan gulamah (J. trachycephalus) merupakan jenis ikan yang hidup di perairan laut dan payau (Robin et al., 1991; Sasaki, 1995). Pakan alaminya adalah ikan kecil, udang, serasah (Kottelat et al., 1993). Ikan ini menggunakan muara-muara sungai untuk berkembangbiak dan memijah atau untuk pengasuhan anak. Ikan gulamah hidup di perairan yang bersuhu rendah, sangat keruh dan berlumpur (Longhurst \& Pauly, 1987). Setiap hari di beberapa jaring yang dipasang oleh nelayan di sungai Barumun ditemukan beberapa ekor ikan gulamah $U$. trachycephalus). Melihat penangkapan ikan gulamah yang dilakukan setiap hari tanpa batas dan melihat kondisi sungai Barumun yang sangat keruh maka peneliti tertarik untuk melakukan penelitian. Tujuan dari penelitian ini adalah untuk mengetahui kepadatan populasi, rasio kelamin, pola pertumbuhan ikan Gulamah (J. trachycephalus), dan hubungan faktor fisikkimia air dengan kepadatan ikan gulamah di sungai Barumun Kabupaten Labuhan Batu.

\section{Bahan dan Metode}

Penelitian ini dilakukan dengan menggunakan metode purposive sampling pada 5 stasiun pengambilan sampel. Stasiun I merupakan daerah kontrol secara geografis terletak pada $02^{\circ} 30^{\prime} 39,81^{\prime \prime}$ LU dan $100^{\circ}$ 8'38,62" BT merupakan daerah mangrove dan jauh dari aktivitas manusia. Stasiun II merupakan daerah muara sungai dekat laut, secara geografis terletak pada $02^{\circ} 38^{\prime} 39,26^{\prime \prime}$ LU dan $100^{\circ} 6^{\prime} 39,53^{\prime \prime}$ BT. Stasiun III merupakan daerah pelabuhan dan pelelangan ikan, secara geografis terletak pada $02^{\circ}$ 33'9,65"LU dan $100^{\circ}$ 8'4,01" BT. Stasiun IV merupakan daerah pemukiman masyarakat, secara geografis terletak pada $02^{\circ} 30^{\prime} 5,82^{\prime \prime} \mathrm{LU}$ dan $100^{\circ} 9^{\prime} 51,04^{\prime \prime}$ BT. Stasiun V merupakan daerah pembuangan limbah pabrik kelapa sawit, secara geografis terletak pada $02^{\circ} 27^{\prime} 47,54$ ' LU dan $100^{\circ}$ 9'45'87' BT.

Pengambilan sampel ikan gulamah $(U$. trachycephalus) dilakukan bersamaan dengan pengukuran faktor fisik-kimia perairan. Pengambilan ikan dilakukan menggunakan jaring dengan panjang jaring 314,7 m dan lebar jaring $1,20 \mathrm{~m}$. Cara pengambilan ikan dilakukan dengan memasang jaring sebanyak 5 ulangan pada masing-masing stasiun dan pada setiap ulangan jaring dibiarkan 1 jam di dalam air. Jaring dipasang mengikuti panjang sungai. Setiap ulangan dilakukan di tempat yang berbeda.

Teknik analisis data dengan menghitunga kepadatang populasi, rasio kelamin, hubungan panjang berat ikan dan distribusi frekuensi panjang.

Analisis korelasi digunakan untuk mengetahui faktor-faktor lingkungan yang berkorelasi terhadap nilai kepadatan ikan. Analisis korelasi dihitung menggunakan Analisis Korelasi Pearson dengan metode komputerisasi SPSS Ver. 17.00

\section{Hasil Dan Pembahasan}

Hasil penelitian di sungai Barumun Kabupaten Labuhan Batu diperoleh ikan gulamah betina dan jantan dengan perbedaan morfologi yang dapat dilihat pada tabel 1 .

Tabel 1.Perbedaan morfologi ikan gulamah jantan dan ikan gulamah betina di sungai Barumun kabupaten Labuhan Batu. 


\begin{tabular}{lll}
\hline \multicolumn{1}{c}{ Ciri - ciri } & \multicolumn{1}{c}{$\begin{array}{c}\text { Ikan } \\
\text { Gulamah } \\
\text { Jantan }\end{array}$} & $\begin{array}{l}\text { Ikan } \\
\text { Gulamah } \\
\text { Betina }\end{array}$ \\
\hline Panjang total & $10,5-21,5 \mathrm{~cm}$ & $\begin{array}{l}10,5-21,6 \\
\mathrm{~cm}\end{array}$ \\
panjang & $3,4-4,4 \mathrm{~cm}$ & $\begin{array}{l}1,8-4,6 \\
\mathrm{~cm}\end{array}$ \\
$\begin{array}{l}\text { kepala } \\
\text { Panjang ekor }\end{array}$ & $2,6-3,7 \mathrm{~cm}$ & $\begin{array}{l}2,4-4,1 \\
\mathrm{~cm}\end{array}$ \\
Berat & $20,3-70,2$ gr & $\begin{array}{l}10,3-80,3 \\
\text { gr }\end{array}$ \\
Warna sirip & Kekuningan & $\begin{array}{l}\text { Keperakan } \\
\text { punggung } \\
\text { dan ekor }\end{array}$ \\
$\begin{array}{l}\text { Bentuk tubuh } \\
\text { Lebih }\end{array}$ & $\begin{array}{l}\text { Lebih } \\
\text { gemuk }\end{array}$ \\
\hline
\end{tabular}

Tabel 2. Kepadatan, kepadatan relatif dan rasio kelamin

\begin{tabular}{|c|c|c|c|c|}
\hline Stasiun & $\begin{array}{c}\text { Jumlah } \\
\text { Ekor }\end{array}$ & $\begin{array}{c}\text { Kepadatan } \\
\left.\text { (Ind } / \mathbf{m}^{2}\right)\end{array}$ & $\begin{array}{c}\text { Kepadatan } \\
\text { Relatif } \\
(\%)\end{array}$ & $\begin{array}{l}\text { Rasio } \\
\text { Kelamin } \\
\left(\delta^{\lambda}: q\right)^{\mathrm{t}}\end{array}$ \\
\hline I & 37 & 0,019 & 54,29 & $1: 1,5$ \\
\hline II & 8 & 0,004 & 11,43 & $1: 7$ \\
\hline III & 8 & 0,004 & 11,43 & $1: 3$ \\
\hline IV & 9 & 0,005 & 14,29 & $1: 8$ \\
\hline V & 6 & 0,003 & 8,57 & $1: 5$ \\
\hline
\end{tabular}

Berdasarkan hasil penelitian diperoleh jumlah ikan gulamah yang banyak di stasiun I, karena kondisi perairan sungai di stasiun I sangat mendukung habitat ikan gulamah. Stasiun I jauh dari aktivitas manusia, memiliki vegetasi mangrove, arus airnya lebih tenang dan terdapat banyak kandungan lumpur. Hal ini sesuai dengan hasil penelitian Wedjatmiko (2008) dan Longhurst \& Pauly (1987), di perairan bengkalis yang sungainya keruh dan berlumpur, spesies yang dominan didapat adalah dari famili Sciaenidae (Johnius sp). Perairan yang keruh dan berlumpur dapat menghalangi cahaya masuk ke badan air sehingga penetrasi cahaya rendah dan suhu air menurun. Vegetasi mangrove mendukung habitat ikan gulamah karena naungan mangrove membuat daerah di bawah vegetasi mangrove lebih sejuk dan dapat menurunkan suhu perairan. Hal ini sesuai pendapat Saputra (2008), populasi ikan gulamah meningkat pada saat musim hujan. Suhu perairan menurun saat musim hujan. Jika dibandingkan dengan hasil penelitian Simanjuntak dan Raharjo (2003) di Perairan Pantai Mayangan, Jawa Barat, dengan perolehan 97 ekor Johnius sp (family scaenidia) yang terdiri dari 39 ekor jantan dan 58 ekor betina, perolehan Johnius $s p$ (family scaenidia) di sungai Barumun lebih sedikit jumlahnya yaitu
68 ekor yang terdiri dari 20 ekor jantan dan 48 ekor betina. Hal ini disebabkan karena perairan pantai merupakan daerah teritorial utama ikan gulamah. Muara sungai hanya digunakan sebagai tempat pemijahan anak dan pemeliharaan anak. diperkirakan kehadiran ikan gulamah di sungai Barumun dipengaruhi oleh pasang surut air laut. Pada saat air pasang ikan terbawa arus ke sungai Barumun. Hal ini sesuai pendapat (Robin et al., 1991; Sasaki, 1995) bahwa Ikan gulamah (J. trachycephalus) merupakan jenis ikan yang hidup di perairan laut dan payau. Jumlah Ikan jantan dan betina yang diperoleh pada lima stasiun adalah I (15 dan 22), II (1 dan7), III (2 dan 6), IV (1 dan 8), dan V (1dan 5). Menurut Samuel dan Adjie (2007), area yang lebih luas sering memiliki variasi habitat yang lebih besar. Kepadatan ikan dalam suatu habitat juga disebabkan oleh beberapa faktor antara lain kehadiran hewan lain (pemangsa dan pesaing), ketidak cocokan habitat, perilaku dan faktor fisika-kimia lingkungan yang berbeda di luar kisaran toleransi ikan tersebut.

\begin{tabular}{|c|c|c|c|}
\hline $\begin{array}{l}\text { Hub } \\
\text { Tab } \\
\end{array}$ & $\begin{array}{l}\text { igan Pa } \\
\text { 3. Data h } \\
\text { ikan }\end{array}$ & $\begin{array}{l}\text { ing-Berat } \\
\text { ungan par }\end{array}$ & $\begin{array}{l}\text { an } \\
\text { ng berat }\end{array}$ \\
\hline$\overline{\mathrm{NO}}$ & Stasiun & $\begin{array}{c}\text { Rata-Rata } \\
\text { Nilai b }\end{array}$ & $\begin{array}{c}\text { Pola } \\
\text { Pertumbuhan }\end{array}$ \\
\hline 1 & I & 3,69 & Allometrik (+) \\
\hline 2 & II & 2,10 & Allometrik (-) \\
\hline 3 & III & 2,01 & Allometrik (-) \\
\hline 4 & IV & 1,93 & Allometrik (-) \\
\hline 5 & $\mathrm{~V}$ & 1,36 & Allometrik (-) \\
\hline
\end{tabular}

Pola pertumbuhan ikan gulamah $U$. trachycephalus) pada stasiun I bersifat allometrik positif, artinya pertumbuhan berat lebih cepat dibandingkan dengan panjang, sedangkan pada stasiun II - V bersifat allometrik negatif artinya adalah pertambahan panjang lebih cepat dibandingkan berat. Hal ini disebabkan arus air yang deras di stasiun II - IV sedangkan pada stasiun I arus airnya lebih tenang. Pencarian atau perolehan makanan juga lebih mudah dilakukan pada stasiun I karena airnya lebih tenang. Arus air yang deras mempengaruhi perilaku ikan pada stasiun IIIV aktif berenang yang mengakibatkan pertumbuhan panjang lebih cepat dibandingkan beratnya. Ikan gulamah juga lebih sulit menangkap makanan di arus air yang deras. Menurut Shukor et al., (2008), ikan yang hidup di perairan arus deras umumnya memiliki nilai b yang lebih rendah dan sebaliknya ikan yang hidup pada 
perairan tenang akan menghasilkan nilai $b$ yang lebih besar. Muchlisin et al., (2010), menyatakan bahwa besar kecilnya nilai b juga dipengaruhi oleh perilaku ikan, misalnya ikan ikan yang berenang aktif menunjukkan nilai $b$ yang lebih rendah bila dibandingkan dengan ikan yang berenang pasif.

Rahardjo et al., (2011) menyatakan pertumbuhan dipengaruhi oleh dua faktor yaitu faktor intrinsik (dalam) dan faktor ekstrinsik (luar). Faktor intrinsik adalah faktor yang timbul dari dalam diri ikan itu sendiri, meliputi sifat keturunan, umur,
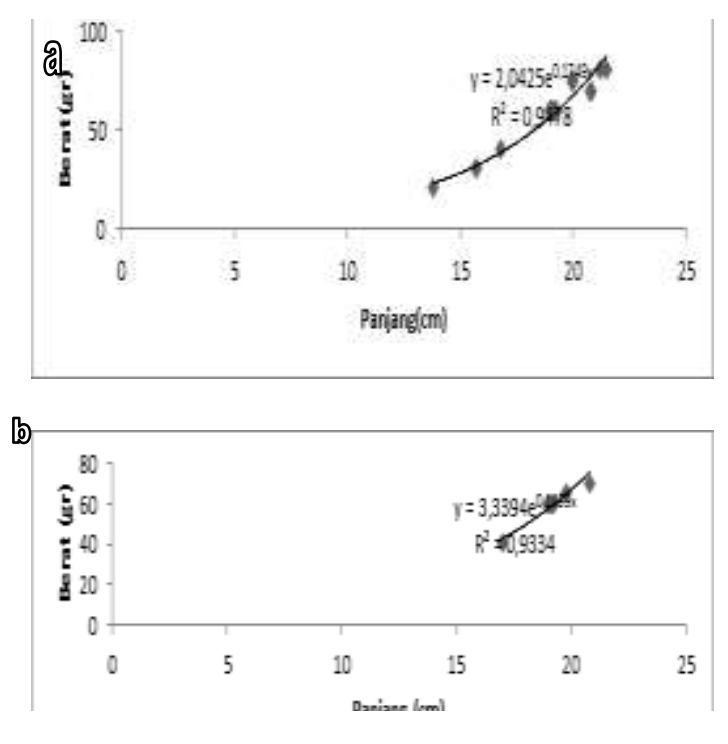

ukuran, ketahanan terhadap penyakit dan kemampuan memanfaatkan makanan. Faktor ekstrinsik meliputi sifat fisik dan kimiawi perairan serta komponen hayati seperti ketersediaan makanan dan kompetisi. Pengaruh masing-masing faktor ekstrinsik di alam sulit dipisahkan satu dari yang lain, karena sering bekerja bersama dalam menimbulkan pengaruh.

Hasil analisis hubungan panjang-berat ikan gulamah (J.trachycephalus) pada stasiun I - V disajikan pada gambar 9 berikut ini:
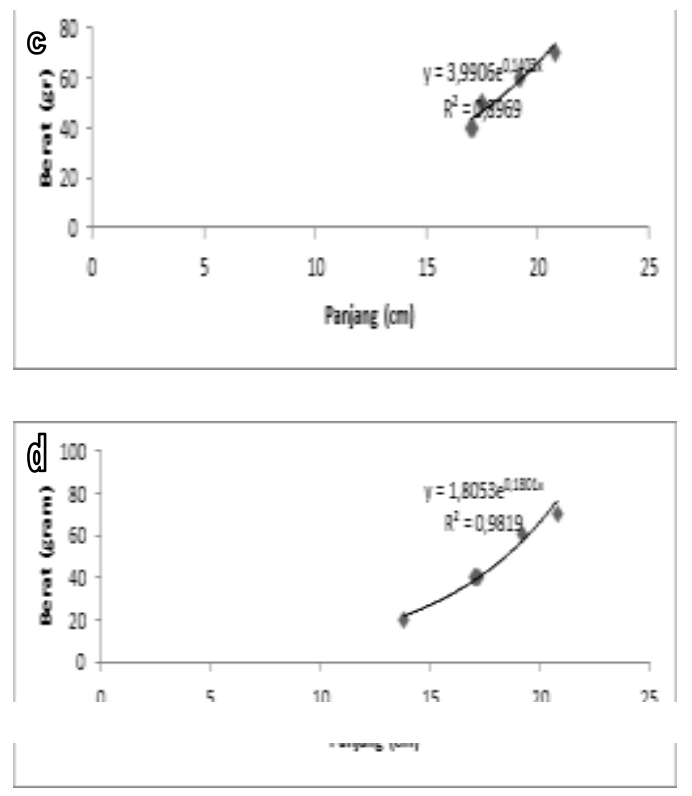

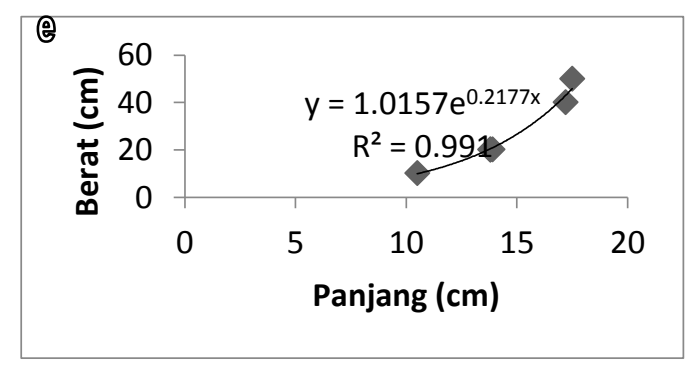

Grafik hubungan panjang berat ikan gulamah (J. trachycephalus) pada stasiun a. stasiun I, b. stasiun II, c. stasiun III, d. stasiun IV,e. stasiun V 


\section{Distribusi Frekuensi Panjang Ikan}

Tabel 4. Tabel Distribusi Frekuensi Panjang Kelas Ikan Gulamah (J.trachycephalus) dari lima Stasiun.

\begin{tabular}{|c|c|c|c|c|c|c|c|}
\hline \multirow[b]{3}{*}{ Kelas } & \multirow{2}{*}{\multicolumn{4}{|c|}{ Frekuensi }} & \multicolumn{3}{|c|}{ Frekuensi Relatif(\%) } \\
\hline & & & & & & & \\
\hline & $\begin{array}{c}\text { Panjang } \\
\text { (cm) }\end{array}$ & Jantan & Betina & $\begin{array}{c}\text { Jantan } \\
+ \\
\text { Betina }\end{array}$ & Jantan & Betina & $\begin{array}{c}\text { Jantan } \\
+ \\
\text { betina }\end{array}$ \\
\hline I & $10,5-12,0$ & 1 & 1 & 2 & 5 & 2,08 & 2,94 \\
\hline II & $12,1-13,6$ & - & - & - & - & - & - \\
\hline III & $13,7-15,2$ & 1 & 3 & 4 & 5 & 6,25 & 5,88 \\
\hline IV & $15,3-16,8$ & 2 & 4 & 6 & 10 & 8,33 & 8,82 \\
\hline $\mathbf{V}$ & $16,9-18,4$ & 1 & 14 & 15 & 5 & 29,17 & 22,06 \\
\hline VI & $18,5-20,0$ & 6 & 21 & 27 & 30 & 43,75 & 39,71 \\
\hline VII & $20,1-21,6$ & 9 & 5 & 14 & 45 & 10,42 & 20,59 \\
\hline Total & & 20 & 48 & 68 & 100 & 100 & 100 \\
\hline
\end{tabular}

Sampel ikan Gulamah (J. trachycephalus) yang didapatkan selama penelitian sebanyak 68 individu dengan panjang 10,5 cm - 21,6 cm yang terdiri dari 20 ekor ikan jantan dan 48 ekor ikan betina. Ikan betina panjangnya berkisar dari 10,5 cm sampai $21,6 \mathrm{~cm}$, sedangkan ikan jantan panjangnya berkisar dari 10,5 cm sampai 21,5 cm. Frekuensi panjang yang terbanyak (modus) pada 18,5 $20 \mathrm{~cm}$. Ukuran panjang yang diperoleh dan dari sifat morfologi yang diteliti menunjukkan bahwa ikan gulamah yang ditemukan dominan ikan gulamah dewasa yang sudah dapat 'melakukan pemijahan. Ditemukannya ikan gulamah pada setiap stasiun diperkirakan untuk melakukan pemijahan dan pencarian makanan.

Hasil penelitian (Suradi et al., 2008) di Cilacap, sampel ikan Gulamah yang didapatkan selama penelitian sebanyak 1.322 individu, yang terdiri dari 462 ekor ikan jantan dan 860 ekor ikan betina. Ikan jantan panjangnya berkisar dari 8,7 cm sampai 22,3 cm. Frekuensi panjang yang terbanyak (modus) pada 15,0 - 15,6 cm. Berat ikan sampel jantan mempunyai kisaran dari 8,5 gram sampai 168,7 gram. Frekuensi berat yang terbanyak (modus) pada 32,8 - 40,8 gram. Johnius sp yang diteliti Simanjuntak dan Rahardjo (2001) di perairan mangrove Pantai Mayangan Jawa Barat berukuran paling panjang $16,1 \mathrm{~cm}$. Dalam hal ini dapat disimpulkan bahwa panjang ikan gulamah di sungai barumun kabupaten Labuhan Batu mendekati panjang ikan gulamah di Cilacap dan lebih besar dari panjang Johnius $s p$ di perairan mangrove Pantai Mayangan Jawa Barat. Berat ikan gulamah di perairan mangrove Pantai Mayangan dan Cilacap lebih besar dari berat ikan gulamah di sungai Barumun kabupaten Labuhan Batu, hal ini kemungkinan disebabkan Pantai Mayangan dan Cilacap merupakan daerah territorial ikan gulamah $U$. trachycephalus). Hal ini sesuai pendapat ( Robin et al., 1991) bahwa ikan gulamah merupakan jenis ikan laut yang hidup di perairan bersalinitas optimal.

\section{Faktor Fisik Kimia Perairan}

Pengukuran faktor fisik kimia selama penelitian dapat dilihat pada tabel 5 berikut:

Tabel 5. Data pengukuran faktor fisik-kimia perairan pada setiap stasiun

\begin{tabular}{lcccccc}
\hline \multicolumn{1}{c}{ Parameter } & Satuan & Stasiun & Stasiun & Stasiun & Stasiun & \multicolumn{2}{c}{ Stasiun } \\
& & I & II & III & IV & V \\
\hline pH & & 6,2 & 8,26 & 8,06 & 6,2 & 8,25 \\
Suhu & ${ }^{\circ} \mathrm{C}$ & 30 & 29,2 & 29,4 & 29,7 & 30,2 \\
Salinitas & o/oo & 6,7 & 10,4 & 5,6 & 4,2 & 5 \\
& & & & & & \\
\hline
\end{tabular}




\begin{tabular}{lcccccc} 
Penetrasi & Meter & 1 & 0,9 & 0,5 & 0,5 & 0,5 \\
DO & $\mathrm{Mg} / \mathrm{l}$ & 6,36 & 7,92 & 8,3 & 7,04 & 8,12 \\
Kejenuhan Oksigen & $\%$ & 84,5 & 104,1 & 109,4 & 93,1 & 108,1 \\
BOD5 & $\mathrm{Mg} / \mathrm{l}$ & 1,2 & 0,9 & 0,9 & 1 & 1,1 \\
Kec.Arus & $\mathrm{m} / \mathrm{det}$ & 0,9 & 1,2 & 0,8 & 1,1 & 0,9 \\
Intensitas & Candela & 1228 & 1106 & 1355 & 1194 & 1028 \\
$\mathrm{~N}$ & $\mathrm{Mg} / \mathrm{l}$ & 16,3 & 45,8 & 154,9 & 106,7 & 13,1 \\
$\mathrm{P}$ & $\mathrm{Mg} / \mathrm{l}$ & 1,09 & 0,95 & 1,17 & 1,23 & 2,74 \\
TDS & $\mathrm{Mg} / \mathrm{l}$ & 807 & 1464 & 976 & 1175 & 91 \\
TSS & $\mathrm{Mg} / \mathrm{l}$ & 115 & 49 & 40 & 79 & 32 \\
COD & $\mathrm{Mg} / \mathrm{l}$ & 42,5 & 24,2 & 31 & 17,4 & 59 \\
\hline
\end{tabular}

Keterangan:

Stasiun I : daerah kontrol

Stasiun II : daerah muara menuju laut

Stasiun III : daerah pelabuhan

Stasiun IV : daerah pemukiman

Stasiun $\mathrm{V}$ : daerah pembuangan limbah pabrik kelapa sawit.

Tabel 6. Hasil Korelasi Kepadatan Ikan dengan Faktor Fisik Kimia Perairan

\begin{tabular}{llc}
\hline No & Parameter & Nilai Korelasi \\
\hline A & Parameter Fisik & \\
1 & $\mathrm{pH}$ & 0,446 \\
2 & Suhu & 0,832 \\
3 & Salinitas & 0,688 \\
4 & Penetrasi Cahaya & 0,347 \\
B & Parameter Kimia & \\
5 & DO & 0,363 \\
6 & Kejenuhan Oksigen & 0,848 \\
7 & BOD & 0,641 \\
8 & Kecepatan Arus & 0,037 \\
9 & Intensitas Cahaya & 0,483 \\
10 & Nitrat & 0,382 \\
11 & Fospat & 0,635 \\
12 & TDS & 0,604 \\
13 & TSS & 0,205 \\
14 & COD & 0,377 \\
\hline
\end{tabular}

Suhu dan kejenuhan oksigen berpengaruh sangat kuat terhadap kepadatan populasi ikan gulamah. Jika suhu naik, populasi ikan gulamah akan menurun. Hal ini sesuai pendapat Longhurst \& Pauly (1987) menyatakan ikan gulamah dapat hidup di air yang sangat keruh dan berlumpur. Air yang keruh dapat menghalangi cahaya masuk ke badan air dan dapat menurunkan suhu air. Saputra (2008) juga menambahkan bahwa populasi ikan gulamah meningkat pada saat musim penghujan. Suhu air menurun pada musim hujan karena intensitas cahaya menurun.

Kejenuhan oksigen yang tinggi juga dapat meningkatkan populasi ikan gulamah. Kondisi kejenuhan oksigen yang tinggi mengindikasikan bahwa terjadinya proses fotosintesis yang berjalan cukup lancar akan menghasilkan oksigen yang banyak sehingga dapat menurunkan suhu perairan Ikan gulamah (Johnius trachycephalus) adalah salah satu ikan demersal. Ikan demersal adalah jenis ikan yang hidup di dasar atau dekat dasar perairan. Di samping itu distribusi atau sebaran ikan demersal sangat dibatasi oleh kedalaman perairan, karena tiap jenis ikan hanya mampu bertoleransi terhadap kedalaman tertentu sebagai akibat perbedaan tekanan air. Semakin dalam suatu perairan akan semakin besar tekanan yang diterima. Oleh karena itu pola penyebarannya juga dipengaruhi oleh dasar perairan yang berfungsi menentukan densitas organisme lain yang merupakan makanan ikan dan menentukan tingkat produktivitas primer terhadap perairan tersebut (Hutabarat, 2000).

\section{Kesimpulan Dan Saran \\ Kesimpulan}

1. Kepadatan ikan gulamah Uohnius trachycephalus) di sungai barumun kabupaten labuhan batu berkisar antara 0,003-0,019 dan kepadatan relatif berkisar antara 8,57\%-54,29\% .

2. Pola pertumbuhan ikan gulamah $U$. trachycephalus) pada stasiun 1 di sungai barumun kabupaten labuhan batu adalah alometrik positif sedangkan pada stasiun II-V, alometrik negatif.

3. Rasio kelamin ikan gulamah jantan dan betina yang masih ideal untuk mempertahankan kelestarian jenisnya hanya terdapat pada stasiun I yaitu 1:1,5. Rasio kelamin pada stasiun II - V kurang ideal. Kondisi ini menunjukkan bahwa populasi ikan gulamah di sungai Barumun kabupaten Labuhan Batu kurang ideal untuk mempertahankan jenisnya. 
4. Suhu dan kejenuhan oksigen memiliki korelasi yang sangat kuat terhadap kepadatan ikan gulamah.

\section{Saran}

Saran untuk penelitian ini adalah perlunya dilakukan penelitian lebih lanjut dengan pemasangan jaring yang lebih lama dan dengan penambahan waktu penelitian yang lebih lama serta pengambilan sampel mengenai reproduksi ikan gulamah Uohnius trachycephalus) tersebut.

\section{Daftar Pustaka}

Campbell, N. A., J. B. Reecee., dan L. G. Mitchell. 2003. Biology Third Edition. Jakarta: Erlangga, Jakarta

Effendie MI. 2002. Biologi Perikanan. Yogyakarta:Yayasan Pustaka Nusantara.

Hutabarat, S., 2000. Produktifitas Perairan dan Plankton. Universitas Diponegoro Semarang

Kottelat, M. and. J Whitten with S.N Kartikasari, and S. Wirjoadmojo.,1993 freshwater Fish of Indoneia and Sulawesi. Periplus Edition (HK) Ltd, in Collaboration with Enviromental Management Project. Ministry of State for population and Enviroment. Jakarta: Republic of Indonesia

Longhurst, A and Pauly. 1987, ecology of Tropical Oceans. Academic Press, San Diego, $407 \mathrm{p}$.

Mahardhini Atifah. 2008. Evaluasi Tingkat Eksploitasi Sumber Daya Ikan Gulamah (Johnius sp) berdasarkan data TPI PPS Cilacap.Saintek Perikanan. Cilacap: Volume $4 . \quad$ Universitas Diponegoro.Fakultas Perikanan dan Ilmu Kelautan

Michael, P. 1994. Metoda Ekologi Untuk Penyelidikan Lapangan dan Laboratorium. Jakarta: UI Press

Muchlisin, Z.A., M,Musman., M.N. Siti Azizah. 2010. Keanekaragaman Ikan Air Tawar di Nanggroe Aceh Darussalam (NAD), Indonesia. Journal of Tropical Fisheries 3(1): 1-9.

Nazir, Mohammad. 1988. Metode Penelitian. Jakarta : Ghalia Indonesia.

Oseanografi Hidro. 1987. Sungai Barumun. Dinas Hidro Oseanografi. Labuhan Batu Sumatera Utara

Pauly,D.1987.Fisheries Research and the demersal fisheries of Southest Asia. In "Fish Population Dynamics" (J. A. Gulland, ed.), $2^{\text {nd }}$ ed. (in press).
Raharjo, M.,. Syafei, D, Affandi, R, Silistiono. 2011. Iktiologi. Lubuk Agung. Bandung

Robins, C.R., R.M. Bailey, C.E. Bond, J.R. Brooker, E.A. Lachner, R.N. Lea \& W.B. Scott, 1991. World fishes important to North Americans. Exclusive of species from the continental waters of the United States and Canada. Am. Fish. Soc. Spec. Publ. (21):243

Saputra. 2008. Evaluasi Tingkat Eksploitasi Sumberdaya Ikan Gulamah (Johnius sp) Berdasarkan Data TPI PPS Cilacap. Program Studi Manajemen Sumberdaya Perairan. Fakultas Perikanan dan Ilmu Kelautan. Universitas Diponegoro. Semarang.

Sasaki, K, 1995. A. review of the Indo-West Pacific Scaenid genus Panna (Teleostei, Perciformes). Jap. J. Ichthyol. 42 (1) : 2737

Shukor, M. Y., A. Samat., A. K. Ahmad dan J. Ruziaton. 2008. Comparative Analysis of Length-Weigth Relationship of Rasbora sumatrana in Relation to the Phy sicochemical Characteristic in Different Geographical Areas in Peninsular Malaysia. Jurnal Ilmiah. Malaysian Applied Biology 37 (1): 21 - 29.

Simanjuntak, C.P.H \& M.F. Rahardjo, 2001. Kebiasaan makanan ikan tetet (Johnius belangerii) di perairan mangrove pantai Mayangan, Jawa Barat. Jurnal Ikhtiologi Indonesia, Vol.1 No.2, Th.2001: 11-17.

Suradi. 2008. Makrozoobentos Sebagai Indikator Kualitas Perairan Sungai. Program Pasca Sarjana Institut Pertanian Bogor

Wedjatmiko, 2008. Komposisi Sumberdaya Ikan Demersal Di Perairan Selat Malaka Biological Aspects Of Demersal Fish In Malacca Strait. Balai Riset Perikanan Laut. Jakarta Utara. 